\title{
FUNDOSCOPIC, OPHTHALMODYNAMOMETRIC, AND TONOMETRIC OBSERVATIONS DURING CARDIOPULMONARY BYPASS IN MAN
}

\author{
O. FARMATI, M.D. *
}

In PREvious investications by the author and others, it was observed that progressive deepening of general anaesthesia lowered retinal arterial blood pressure disproportionately to the decrease in radial arterial blood pressure. This phenomenon occurred earlier with halothane than with cyclopropane and was reversible by reducing the depth of anaesthesia. ${ }^{1}$

This investigation was continued adding observations of the human eye during cardiopulmonary bypass to assess the relationship of the retinal artery to other systemic arteries following various physiological and pharmacological alterations. Consideration was given to the fact that the vascular distribution of the internal carotid artery in man is subject to minimal neurogenic control. Also, pressure changes could be observed better under nonpulsatile flow conditions of the bypass period when the effect of the oculo-cardiac reflex over the carotid circulation is abolished.

\section{METHOD}

Observations consisted of the following procedures:

1. Fundoscopic observations performed by direct opthalmoscopy.

2. Retinal arterial pressure measurements were made using the Baillart type ophthalmodynamometer. The principle, technique, and limitations of opthalmodynamometry were defined in an earlier publication in this Journal. ${ }^{1}$ The mean retinal arterial pressure was estimated by adding two-thirds of the systolic minus diastolic resultant to the diastolic pressure. During the bypass period, with essentially nonpulsatile flow, the mean retinal arterial pressure was considered as that minimal pressure necessary, with the dynamometer, to produce visible collapse of the central retinal artery. The Magitot-Baillart conversion table was used for the final interpretation of the data in millimetres of mercury.

3. The intraocular tension was determined with the Schiotz tonometer. The tonometer was not used on the same eye on which the dynamometer had been used because of possible intraocular pressure changes induced by mydriatics and repeated applications of the dynamometer on the same eye.

4. Major systemic arterial pressure was measured via an intra-arterial polyethylene catheter and strain gauge in the radial or femoral artery. Mean intraarterial pressures were obtained by use of an electronic averaging device in the strain-gauge amplifier.

\footnotetext{
-Assistant Professor, Department of Anesthesiology, and Clinical Research Associate, Department of Pharmacology, School of Medicine, University of Pittsburgh. Correspondence and requests for reprints should be sent to Dr. Farmati at the Department of Anesthesia, Presbyterian University Hospital, 230 Lothrop Street, Pittsburgh, Pa. 15213.
} 
5. Arterial $\mathrm{Pa}_{2}, \mathrm{~Pa}_{\mathrm{CO}_{2}}$, and $\mathrm{pH}$ determinations were done simultaneously with the other measurements.

Readings were obtained as follows. (1) Before and after bypass with the patient under $\mathrm{N}_{2} \mathrm{O}-\mathrm{O}_{2}$-halothane-relaxant anaesthesia and controlled ventilation, and when all clinical parameters appeared stable. (2) During bypass with the patient under $\mathrm{N}_{2} \mathrm{O}-\mathrm{O}_{2}$-halothane-relaxant anaesthesia and when conditions appeared stable and uncomplicated.

Retinal arterial pressure measurements, tonometric measurements, and radial or femoral arterial pressure measurements were done on twelve patients between the ages of two and fifty years.

Three additional patients were investigated under similar conditions with the exception that one dose of $0.1 \mathrm{mg}$. of phenylephrine was added "intra-arterially" to the oxygenator. The average age of these three patients was eight years and their weight was about $20 \mathrm{~kg}$. Four ophthalmodynamometric and tonometric readings were performed on these three patients during bypass at five-minute intervals. Observations at shorter intervals were not desirable because expelling of the aqueous humour from the anterior chamber of the eye might interfere with the accuracy of the readings.

The data do not include the period of the cardiopulmonary bypass required for disappearance of the effect of phenylephrine because of the technical difficulties encountered in performing these measurements in the operating room. Children were particularly difficult subjects because the number of measurements that could safely be made without injury to the eye was limited.

The temperature of the patients was monitored by an oesophageal thermistor probe. The average temperature readings during the interval over which ocular measurements were made ranged from $35^{\circ}$ to $36.5^{\circ} \mathrm{C}$.

\section{RESULTS}

The fundus of the eye became very pale with initiation of total cardiopulmonary bypass. Approximately 60 to 70 seconds elapsed before a good return of normal circulation in the retinal vessels was observed. This usually coincided with the return of the electroencephalogram to pre-bypass configuration (fronto-occipital lead). It was difficult to detect any difference in colour between retinal arteries and veins for approximately five minutes thereafter. The blood columns in peripheral retinal vessels appeared fragmented or sludged in six of fifteen cases whenever the pump flow rate fell under $1.5 \mathrm{~L} . / \mathrm{m}^{2}$ of body surface, and disappeared when the flow rate of the pump was again increased. The fundoscopic appearance of the macula lutea was normal during the entire procedure. An interesting observation was made on patients when the bypass lasted longer than one and a half hours. In these cases, there developed an accentuated sheen of the entire internal retinal surface and external vitreous body. This can be interpreted as excessive hydration of these structures, probably due to an incipient oedema.

The ratio of the central retinal arterial blood pressure to the radial or femoral intra-arterial blood pressure before and after the pump confirmed our previous 

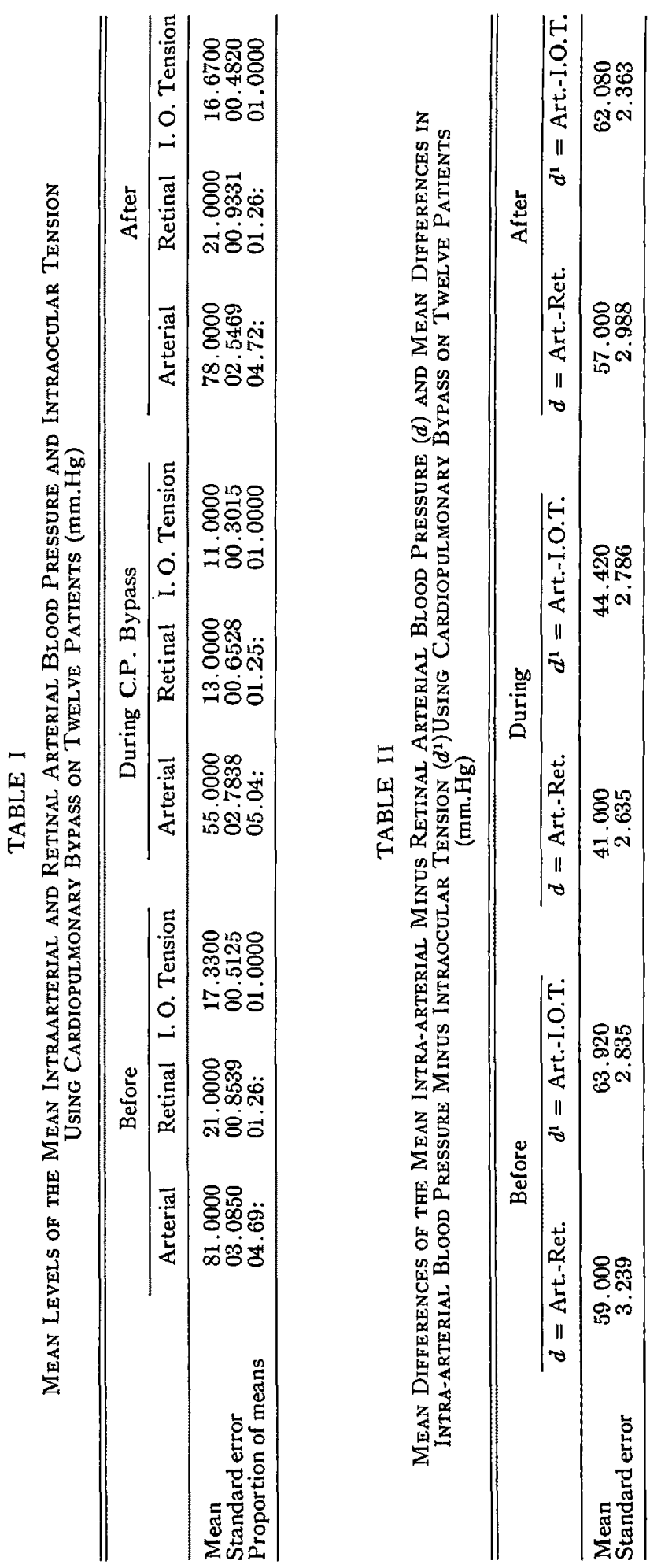
findings regarding the retinal arterial blood pressure drop during general anaesthesia in humans. ${ }^{1}$

The mean value, the standard error, and the proportion of the peripheral intraarterial, retinal arterial, and intraocular pressures, before and after the pump, were in close agreement (Table I).

The means of the pressure levels and the mean differences between pressures obtained during the bypass differ from corresponding values obtained during spontaneous circulation. During the period of bypass, a drop in all mean pressure levels occurred. In addition, the differences between intra-arterial pressure and intraocular tension showed a decrease as compared with corresponding differences before and after bypass (Table II). These changes do not essentially alter the proportions that exist between the mean levels of pressure for the three periods. Intraocular tension, retinal arterial pressure, and peripheral intra-arterial pressure remained throughout in a relationship of approximately 1:1.25:5.00.

For the three patients who received phenylephrine, the mean levels of intraarterial and retinal arterial blood pressure and intraocular tension appear comparable for the periods preceding and following bypass (Table III). During the early stages of bypass, all three mean pressures decreased proportionally when compared to corresponding values prior to bypass. However, when the phenylephrine was added to the pump, the mean level of the intra-arterial pressure

TABLE III

Mean Levels of the Mean Intra-arterial and Retinal Arterial Blood Pressure and Intraocular Tension Using Cardiopulmonary Bypass on Three Patients who Received Phenyle phrine During the Pump (mm.Hg)

\begin{tabular}{lcrr}
\hline \hline & Intra-arterial & Retinal & I. O. tension \\
\hline Before & & & \\
Mean & 61.0000 & 21.0000 & 15.6700 \\
Standard error & 6.0100 & 1.6670 & 0.6663 \\
Proportion of means & $4.0400:$ & $1.3800:$ & 1.0000 \\
During & & & \\
Mean & 51.0000 & 11.0000 & 10.3300 \\
Standard error & 1.6667 & 0.6667 & 0.3333 \\
Proportion of means & $5.0000:$ & $1.0900:$ & 1.0000 \\
Mean* & 66.0000 & 13.0000 & 11.0000 \\
Standard error & 3.3310 & 1.0000 & 0.8167 \\
Proportion of means & $6.0600:$ & $1.1800:$ & 1.0000 \\
Mean & 83.0000 & 13.0000 & 11.3300 \\
Standard error & 3.3310 & 0.8818 & 0.8818 \\
Proportion of means & $7.3500:$ & $1.1800:$ & 1.0000 \\
Mean & 86.0000 & 14.0000 & 11.3300 \\
Standard error & 3.3331 & 1.4526 & 0.6667 \\
Proportion of means & $7.6500:$ & $1.2900:$ & 1.0000 \\
Mean & 90.0000 & 16.0000 & 10.0000 \\
Standard error & 0.0000 & 0.5771 & 0.0000 \\
Proporti $:$ of means & $9.0000:$ & $1.6000:$ & 1.0000 \\
After & & & \\
Mean & 63.0000 & 20.0000 & 13.6700 \\
Standard error & 3.3333 & 0.0000 & 1.0536 \\
Proportion of means & $4.6300:$ & $1.4600:$ & 1.0000 \\
\hline tFirting & &
\end{tabular}

*First reading following the one dose of phenylephrine. 
increased markedly without changing the flow rate of the pump, whereas there was only a slight change in mean levels of the retinal arterial pressure and of the intraocular tension. The proportions existing among mean levels of pressures during bypass ranged from 1:1.09:5.00 before adding phenylephrine to 1:1.60:9.00 after adding phenylephrine, respectively, for intraocular, retinal artery, and intra-arterial pressures.

When mean differences in pressures were considered for these three patients, the mean differences before and after bypass appear comparable (Table IV). However, for the period of bypass, after the addition of the phenylephrine, the mean differences between pressures increased steadily as the period of bypass progressed. This increase appears to be almost entirely accounted for by the increase in the peripheral intra-arterial pressure. Arterial blood gases and $\mathrm{pH}$ measurements showed slight variations which appeared to be within normal limits.

TABLE IV

Mean Differences of the Mean Intra-arterial Minus Retinal Arterial Blood Pressure (d) and Mean Differences in InTRa-ARTerial BloOd Pressure Minus Intraocular Tension $\left(d^{1}\right)$ Using Cardiopulmonary Bypass on Three Patients who Received Phenylephrine during the PuMP (mm. Hg)

\begin{tabular}{lcc}
\hline & Arterial-retinal $(d)$ & Arterial-I.O. tension $\left(d^{1}\right)$ \\
\hline Before & & \\
Mean difference & 41.0000 & 47.6700 \\
Standard error & 6.6663 & 5.3645 \\
During & & \\
Mean difference & 40.0000 & 41.3300 \\
Standard error & 2.3323 & 1.8547 \\
Mean difference & 53.0000 & 55.6700 \\
Standard error & 2.9631 & 2.8479 \\
Mean difference & 70.0000 & 72.0000 \\
Standard error & 3.6055 & 2.5159 \\
Mean difference & 72.0000 & 75.3300 \\
Standard error & 2.1610 & 3.7119 \\
Mean difference & 74.0000 & 80.0000 \\
Standard error & 0.8165 & 0.0000 \\
After & & \\
Mean difference & 43.0000 & 49.6700 \\
Standard error & 3.3333 & 2.1863 \\
\hline
\end{tabular}

*First reading following the one dose of phenylephrine.

\section{Comment}

The significance of the fragmentation of the blood column in the retinal vessels which occurs within seconds following circulatory arrest has not yet been determined. A subsequent migration of the contents in the retinal vessels toward the papilla, particularly in veins, is attributed to gravitation and to propellent elasticity of the vessels. Persistence of motion of those segments is considered a favourable prognostic index related to the outcome of cardiovascular resuscitation. Hypothermia is believed to prevent fragmentation., ${ }^{2,8}$ Different degrees of 
segmentation of the blood columns in the retinal vessels was also reported in the thromboembolic central retinal arterial occulsion, decompression sickness, "pulseless disease,"3 and macroglobulinaemia. It may be difficult to differentiate from vasospasm where complete interruption of the blood column is not present. ${ }^{3}$ In our observations, the fragmentation became evident in peripheral retinal vessels when the pump flow rate was 30 per cent under the accepted "ideal" level of $2.2 \mathrm{~L} . / \mathrm{min} . / \mathrm{m}^{2}$ of body surface. Correct interpretation of the aetiology of these findings is beyond our knowledge at the present time.

The retinal artery is a terminal branch of the opthalmic artery which in turn arises from the internal carotid artery proximal to the cerebral arteries. According to Poiseuille's Law, the pressure in the retinal arteries should be a resultant of the difference between the pressure in the internal carotid artery and the resistance to flow in the peripheral cerebral arterial network primarily determined by the diameter of the cerebral arterioles.

Consequently, contraction of the carotid arteries will produce a decrease in the systolic retinal arterial pressure, and their dilatation an increase in retinal arterial diastolic pressure. Constriction of the peripheral cerebral arteriolar network will cause an increase in the systolic retinal arterial pressure, and their dilatation a decrease in the diastolic retinal arterial pressure. ${ }^{2}$ In other words, the relative systemic hypertension produced by phenylephrine was not reflected by changes in retinal arterial pressures, thus suggesting a dominant cerebral arteriolar dilatation and selective decrease of the peripheral resistance of the central nervous system ${ }^{4}$ because of general anaesthesia, ${ }^{5}$ low perfusion pressure, heparinization, and the absence of pulsatile flow. The autoregulation of the circulation in the brain and retina in similar situations is facilitated by the absence of effective sympathetic vasoconstriction in man.,6 However, rigid application of Poiseuille's Law for the interpretation of our findings is questionable. This law is more applicable to laminar flow in rigid tubes than to turbulent flow in elastic vessels; blood is a non-Newtonian fluid, and this law is only an approximation for tubes having a diameter less than $0.1 \mathrm{~mm}$. A mechanical interpretation of blood pressure differences is further complicated by the vascular anatomy of the area. The postorbital branches of the ophthalmic artery anastomose with facial branches of the external carotid artery, thus resembling the circle of Willis where the blood flow is the resultant of opposing systolic waves of the internal carotid and vertebral arteries. ${ }^{7}$

The behaviour of the intraocular tension, and likewise the retinal arterial pressure, toward the systemic arterial pressure was not an unexpected finding. In general terms, a steady state of intraocular tonicity is a resultant of the relationships between the intraocular content and the rigidity of the scleral coat. A decrease of intraocular tension following the arterial hypotension in the ophthalmic artery is a consequence of a collapse of the uveal vascular bed, decreasing, in this way, the volume of the intraocular content. If the arterial hypotension is prolonged, a decrease of the aqueous humour production by the ciliary body could be a contributory factor to the intraocular hypotonicity.

The failure of phenylephrine to raise the intraocular pressure despite its systemic arterial hypertensive effect demonstrated not only the close anatomical 
origin of the uveal and retinal circulation (i.e., the internal carotid tributary) but also the similarity of pharmacodynamic answers in these situations.

\section{SUMMARY}

Ophthalmoscopic observations, retinal arterial pressure determinations, and intraocular tension measurements have been made during general anaethesia and cardiopulmonary bypass in fifteen patients.

Examination of the eye ground disclosed some degree of segmentation of the blood column in peripheral retinal vessels in six of fifteen cases. These findings disappeared after increase and stabilization of the flow delivered by the bypass pump.

The intraocular tensions and the retinal arterial pressures were correlated with the systemic intra-arterial blood pressure before, during, and after cardiopulmonary bypass. These relationships remained relatively constant.

Three patients received one dose of phenylephrine in the oxygenator during bypass, with an immediate rise in the systemic pressure. However there did not seem to be a corresponding rise in retinal artery pressure or intraocular tension.

\section{RÉSUMÉ}

Au cours de recherches antérieures, dont les résultats ont été publiés dans ce journal par les auteurs soussignés et d'autres chercheurs, l'on a fait observer que l'approfondissement de l'anesthésie générale abaissait la pression artérielle rétinienne de façon disproportionnée à l'abaissement de la pression artérielle radiale. Ce phénomène est apparu plus précocement avec l'halothane qu'avec le cyclopropane et il était réversible en diminuant la profondeur de l'anesthésie. Nous avons modifié cette recherche au cours de la circulation extracorporelle alors que les changements de pression sont plus faciles à observer car alors le courant n'est pas pulsatile. Les observations ont été faites de la façon suivante: (1) ophtalmoscopie directe; (2) mesures de la pression artérielle rétinienne à l'aide de l'ophtalmodynamomètre du type Baillart; (3) détermination de la tension intraoculaire à l'aide du tonomètre de Schiotz; (4) prises de la pression artérielle systémique à l'aide d'un cathéter intra artériel et d'un monomètre à ressort; (5) la recherche dans le sang artériel de la $\mathrm{Po}_{2}$, de la $\mathrm{Pco}_{2}$ et du $\mathrm{pH}$. Ces recherches ont été effectuées sur 15 malades, dont trois ont reçu une dose de phényléphrine dans l'oxygénateur.

L'examen du fond de l'œil a révélé une segmentation de la colonne sanguine dans les vaisseaux rétiniens périphériques chez 40 pour cent des cas de circulation extracorporelle; cette observation est disparue après l'augmentation et la stabilisation du courant de la pompe à un débit moyen de $2.2 \mathrm{~L} . / \mathrm{min} . / \mathrm{m}^{2}$ de surface corporelle. La tension intraoculaire et la tension artérielle rétinienne étaient comparées à la tension artérielle systémique avant, durant et après la circulation extracorporelle. La relation entre ces trois tensions est demeurée relativement constante durant cette période chez trois malades; à la suite de l'injection de 
phényléphrine, nous avons observé une élévation de la tension artérielle périphérique sans écho sur les tensions de l'artère rétinienne et de l'œil.

Selon la loi de Poiseuille, la tension dans les artères de la rétine et de la papille (celles-ci régissant principalement la tension intraoculaire) est la résultante de la tension dans la carotide interne et la résistance au courant sanguin dans le treillis artériollaire cérébral périphérique. Il nous semble logique d'assumer que l'absence d'élévation de tension dans les artères de la rétine et de la papille à la suite de l'injection de phényléphrine est due à la dilatation artériollaire cérébrale et à la diminution sélective de la résistance dans le système nerveaux central, à cause de l'anesthésie générale, la basse tension de perfusion, l'héparinisation et l'absence d'un courant pulsatile.

\section{ACKNOWLEDGMENTS}

The author wishes to thank Drs. A. Freeman, E. Nagel, and R. Tenicela for permission to study their patients, and Dr. P. Safar, Professor and Chairman, University of Pittsburgh School of Medicine, Department of Anesthesiology, for critical review of the data.

\section{REFERENCES}

1. Farmati, O.; Freeman, A.; \& Moya, F. Changes in Retinal Arterial Blood Pressure during Cyclopropane and Halothane Anaesthesia in Children. Canad. Anaesth. Soc. J. 14:26 (1967).

2. Duke-Elder, S. System of Ophthalmology, vol. 7. St. Louis: Mosby (1963), pp. 355-62, p. 322 .

3. Kevorkian, J. The Eye in Death. Clin. Sympos. 13: 51 (1961).

4. Green, H.; Rapela, C.; \& Conrad, M. Resistance and Capacitance Phenomena in Terminal Vascular Beds. Circulation. 2: 935 (1963).

5. Price, H. L. \& Cohen, P. Effects of Anesthetics on the Circulation. Springfield: Charles Thomas (1964), pp. 70-73, 209-14, 278-83.

6. Best, C. H. \& Taylor, N. B. The Physiological Basis of Medical Practice. 7th ed, Baltimore: Williams Wilkins (1961), pp. 205-31.

7. Desvignes, P. Similitudes et differences entre les circulations retiniennes et cerebrales. Semaine Hôp. Paris, no. 26 ( 1963 ), p. 1244. 